\title{
Apresentação: a cidade, as artes e a cultura
}

\section{Paula Abreu e Claudino Ferreira}

\section{OpenEdition}

\section{Journals}

\section{Edição electrónica}

URL: http://journals.openedition.org/rccs/1104

DOI: $10.4000 /$ rccs. 1104

ISSN: 2182-7435

\section{Editora}

Centro de Estudos Sociais da Universidade de Coimbra

Edição impressa

Data de publição: 1 dezembro 2003

Paginação: 03-06

ISSN: 0254-1106

\section{Refêrencia eletrónica}

Paula Abreu e Claudino Ferreira, « Apresentação: a cidade, as artes e a cultura », Revista Crítica de Ciências Sociais [Online], 67 | 2003, posto online no dia 01 outubro 2012, consultado o 22 setembro 2020. URL : http://journals.openedition.org/rccs/1104 ; DOI : https://doi.org/10.4000/rccs.1104 


\section{Apresentação: a cidade, as artes e a cultura}

As cidades são, talvez desde sempre, o lugar privilegiado da arte e da cultura, sobretudo das suas expressões mais formalizadas. São-no a diversos títulos: enquanto contextos privilegiados da produção e da criação artística e cultural; enquanto palcos ou cenários principais da apresentação e da performance, da participação e do consumo culturais; e, por último, enquanto objectos, em si mesmas, de representação estética e de valor artístico, cuja singularidade reside tanto na sua configuração arquitectónica como nas formas da vida social e cultural que pulsam no seu interior.

Se podemos reconbecer nesta cumplicidade um traço constante da modernidade, em que a história da cultura e da arte e a(s) história(s) da(s) cidade(s) se tocam e influenciam continuamente, devemos de igual forma atentar no carácter particularmente agudo e renovado que esta relação assume nas sociedades contemporâneas. Nas últimas décadas, no mundo ocidental, e na Europa em particular, a cultura foi ganhando maior relevo nas politicas urbanas e nos modos de conceber e planear a vida nas cidades. Vários aspectos convergem nesse sentido. Desde logo, a generalização da ideia de que o acesso à cultura deve ser parte constitutiva da cidadania contemporânea. Essa ideia vai naturalmente a par com a prevalência dos estilos de vida e das expectativas das classes médias urbanas mais escolarizadas, que vêem na cultura, no lazer e na estetização dos ambientes em que circulam ingredientes importantes da sua integração sócio-espacial.

Acresce a isto que às actividades culturais vem sendo reconbecido um contributo cada vez mais significativo para a economia das cidades. Este reconhecimento, que vem sustentando o investimento, público e privado, na cultura como forma de promover a regeneração socioeconómica das cidades, não está isento de ambiguidades, nomeadamente no que se refere à avaliação do impacto directo que a aposta cultural tem sobre as economias locais. O mesmo pode dizer-se, de resto, das tendências que mais recentemente têm associado a acção cultural a políticas de integração e coesão social. Tanto num caso como no outro, no entanto, o que é talvez mais relevante notar é que o valor económico e social da cultura surge muito directamente associado ao seu valor simbólico e de representação. A revalorização das artes e dos recursos culturais locais constitui hoje um elemento fundamental das estratégias de promoção e pro- 
jeç̧ão da imagem das cidades nos mercados externos, assim como do reforço da identificação interna das comunidades locais. E, por essa via, esboçam-se novas visões para as cidades e a cultura, ao mesmo tempo que se afirmam protagonismos e notoriedades, individuais e grupais, nas arenas cultural, politica e social.

No momento em que se encerra o primeiro ensaio de uma cidade consagrada como Capital Nacional da Cultura (Coimbra 2003), e ainda no rescaldo da experiência vivida pelo Porto como Capital Europeia da Cultura, torna-se evidente o modo como, entre nós, se vêm manifestando novas formas de cumplicidade entre a cultura e a cidade, as politicas culturais e as políticas urbanas. Cumplicidade manifesta na crescente atenção que, num quadro generalizado de sub-financiamento da cultura, as políticas locais vêm concedendo aos recursos e às actividades culturais e lúdicas, equacionados como instrumentos de regeneração socioeconómica ou de promoção simbólica das cidades e das suas elites. Cumplicidade igualmente presente nas múltiplas maneiras como, em articulação com essas políticas, os agentes culturais - instituições, criadores e mediadores - vêm redesenhando estratégias de obtenção de recursos e de mobilização de públicos, que sustentem e legitimem a sua actividade.

As formas como, neste contexto, a cultura se apresenta e representa (n)a cidade, enunciam novas e heterogéneas modalidades de articulação entre cultura, política e mercado, cuja expressão é tão relevante para a redefinição da produção do espaço urbano como para a reconfiguração da própria esfera cultural. Desenha-se aqui um inestimável campo de pesquisa e questionamento que, embora tenha hoje uma forte expressão no estrangeiro, só muito recentemente, e de modo tímido, tem vindo a emergir em Portugal.

Tendo presente este contexto geral, e abrindo um espaço de debate em torno de algumas questões que ele suscita contemporaneamente, a Revista Crítica de Ciências Sociais propõe um número subordinado ao tema Cidade/Artes/ Cultura. O volume é composto por um conjunto de textos que sugerem abordagens distintas sobre algumas das formas que plasmam a intensa presença da cultura no quotidiano das cidades. Os artigos incluidos não definem qualquer programa sistemático de abordagem das problemáticas sugeridas pelo tema geral. O seu principal interesse reside, antes, na heterogeneidade dos objectos de análise e na diversidade de perspectivas analiticas. Eles permitem ilustrar a actual complexidade das relações que se tecem entre cultura e cidades e suscitam caminhos de indispensáveis reflexões críticas.

Jean-Louis Fabiani e Emmanuel Éthis propõem-nos uma reflexão sobre o percurso histórico do Festival de Avignon, remetendo-nos para uma interessante discussão acerca do lugar dos grandes eventos culturais na mobilização e na constituição dos públicos da cultura. A abordagem destes autores é parti- 
cularmente interessante pelo facto de pôr em relevo a importância de um conjunto de factores contextuais, associados à história singular do Festival, à sua localização em Avignon - cidade com um importante património histórico e monumental - e às dinâmicas geradas pelo seu projecto artístico na 'fabricação' de um público específico, o "público de Avignon".

Mari Paz Balibrea apresenta uma análise sobre as políticas de renovação urbana que têm tomado a cultura, e em particular o património histórico e arquitectónico, como elemento central de projectos de reconversão das cidades, nomeadamente através do desenvolvimento das indústrias do lazer e do turismo. Convida-nos para uma viagem pela cosmopolita Barcelona, que lhe permite esboçar uma reflexão crítica acerca dos efeitos de homogeneização e de hegemonia simbólica, induzidos pelos critérios, os conteúdos e os processos de definição dessas políticas. Serve-lhe de ilustração o caso dos achados arqueológicos do Mercat del Born. Na sua narrativa, clarifica-se o modo como o projecto de conservação e museologização das ruinas sobrepôs os interesses politicos e económicos associados ao modelo de reconversão pós-industrial da cidade aos interesses específicos e necessariamente mais heterogéneos das actuais populações residentes.

André Brito Correia lança um olhar sobre as relações que a criação artística contemporânea mantém com os espaços urbanos. Contando-nos a história de três produçôes teatrais que recentemente tiveram lugar na cidade de Coimbra, realizadas no âmbito da Capital Nacional da Cultura, o autor mostra-nos o modo como a criação teatral pode contribuir para uma apropriação estética de espaços na cidade, não tanto como cenários indiferenciados, mas como contextos cuja densidade simbólica pode ser revertida para os universos da representação dramática.

Com Helena Santos, retoma-se o debate acerca da constituição dos públicos da cultura na cidade e aprofunda-se a discussão sobre as reconceptualizações a que esta noção é sujeita em diversos contextos de inserção da actividade cultural. O texto apresenta-nos a análise de uma experiência inédita no nosso país, a produção da ópera Demolição - a história que ides ver, conduzida pelo Departamento Educativo da Casa da Música, no Porto, em 2002. Trata-se de uma experiência de envolvimento e participação de populações urbanas, tidas como socialmente excluídas ou marginais, na criação e produção de raiz de uma obra musical. Perspectivada pela autora como uma ilustração das novas concepções de educação e inclusão social pela arte, a experiência é aqui apresentada como o resultado de delicados e complexos processos de uma mediação social e artística autorizada.

Por último, cabe aqui destacar o dossier dedicado a Georg Simmel. Nele se publicam, pela primeira vez, as traduções portuguesas dos estimulantes ensaios 
que o autor dedicou às cidades históricas de Roma, Florença e Veneza. Com esta publicação, contribui-se para a divulgação, entre o público português, da obra de um autor que, tendo estado longamente afastado do panteão dos clássicos da sociologia, se revela, no entanto, uma preciosa fonte inspiradora para a reflexão sobre o fenómeno urbano moderno, um dos muitos temas em que se desdobra o inestimável legado de Simmel. Como refere Carlos Fortuna no texto que abre o dossier, e que nos desvenda uma série de caminhos para percorremos as densas reflexões filosóficas e sociológicas a que Simmel se entrega, o carácter pioneiro destes textos reside desde logo na atenção que conferem "à articulação da arte e da estética com o espírito e a vida da cidade". Na avaliação que Simmel nos oferece sobre a dimensão estética das três cidades bistóricas italianas, sobressai permanentemente o elemento temporal da cidade $e$, com ele, a tensão entre a natureza e o espírito, que enforma a configuração da vida e da cultura urbanas.

Essas reflexões permitem-nos avaliar o modo como a cidade moderna foi desde cedo equacionada nas suas dimensões estéticas e simbólicas e, assim, erigida, em si mesma, à condição de obra de arte. Decorrido cerca de um século, os ensaios de Simmel, para lá do seu valor intrinseco, proporcionam-nos um conjunto de intuições e uma série de elementos de contraste que se revelam preciosos para a compreensão dos actuais processos de reconfiguração estética das cidades. Em última análise, eles permitem-nos relativizar, e complexificar, as avaliações sobre as sinergias actualmente estabelecidas entre cultura, artes e dinâmicas urbanas, um terreno que se vem impondo como incontornável tanto do ponto de vista sociológico, como político.

Paula Abreu

Claudino Ferreira 